\title{
The research of reinforced RPC Concrete with steel fibers and polypropylene fiber
}

\author{
Li-guang XIAO ${ }^{1, a}$, Bo JIANG ${ }^{1, b}$ \\ ${ }^{1}$ School of Materials Science and Engineering, Jilin Jianzhu University, Changchun 130118,China \\ axlg627@163.com, b191426255@qq.com
}

Keywords: steel fiber/polypropylene fiber composite doped; RPC; mechanism analysis; synergies

\begin{abstract}
Reactive powder contrete (RPC) is a high performance concrete. According to our results show that the single steel fiber when mixed with RPC, 28d highest compressive strength of RPC is 80.3MPa, flexural strength $13.45 \mathrm{MPa}$, respectively, higher than the reference RPC $14.96 \%$ and 18.92\%; Single polypropylene fiber when mixed with RPC, 28d highest compressive strength of RPC is $80.5 \mathrm{MPa}$, flexural strength $13.5 \mathrm{MPa}$, respectively higher than the reference RPC $15.25 \%$ and $19.36 \%$; Steel fiber content is $1.5 \%$, polypropylene fiber content is $0.7 \%$ when, RPC's $28 \mathrm{~d}$ compressive strength up to 81.32MPa, flexural strength up to $14.37 \mathrm{MPa}$, respectively higher than the reference RPC is $16.42 \%$ and $27.06 \%$. And impact strength and resistance to splitting tear strength reached at the highest for $1.1 \mathrm{MPa}$ and $8.51 \mathrm{Mpa}$, respectively higher $144.4 \%$ and $143.7 \%$ than the reference RPC. Two double doping greatly improved toughness and ductility of RPC, fully reflects the composite materials"Synergistic".
\end{abstract}

\section{Introduction}

Reactive Powder Concrete (RPC) mainly consists of cement, quartz sand, superplasticizer, silica fume, fly ash, etc composition. It is a kind of high strength concrete by adding different types of fiber, reinforced RPC ductility and toughness, thus enhancing the durability of RPC.

\section{Test}

Raw materials. Cement using P.O42.5R ordinary portland cement, specific surface area is $802.9 \mathrm{~m}^{2} / \mathrm{kg}$; Coarse, medium and fine grading of 1:4:10 quartz sand; Fly ash is a $45 \mu \mathrm{m}$ square hole sieve residue $19.3 \%$ after machine grinding $15 \mathrm{~min}$ measured, a specific surface area is $1454.5 \mathrm{~m}^{2} / \mathrm{kg}$; Silica fume $45 \mu \mathrm{m}$ square hole sieve margin used was $7.8 \%$, a specific surface area is $20379.7 \mathrm{~m}^{2} / \mathrm{kg}$; Reducing agent used is polycarboxylate superplasticizer; Fiber is used in length $12 \mathrm{~mm}$, diameter of $0.265 \mathrm{~mm}$ copper-plated steel fibers and a length of $8 \sim 15 \mathrm{~mm}$ monofilament polypropylene fibers.

Mix proportion. For comparison steel fibers, polypropylene fibers, and two dual-doping enhancement to the RPC, it was carried out in four series of comparative experiments. RPC reference cementitious material made of cement, fly ash and silica fume composition, incorporation of polycarboxylate superplasticizer, cementitious materials $0.4 \%$ of the total mass; Water-cement ratio is 0.27 .

\section{Test results}

Single steel fiber influence on Mechanical Properties of of RPC. RPC single mixed with copper steel fiber 3d, 28d compressive and flexural strength as well as the Figure 1: 

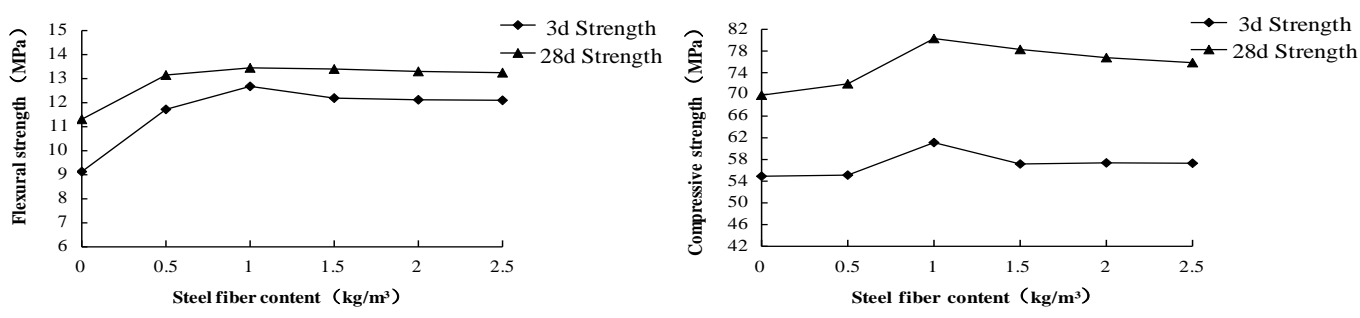

Fig.1 The effects of different dosage strength of steel fiber RPC

It can be seen by Figure 1, RPC 28d compressive strength of up to 80.3MPa, 14.96\% increase over the reference RPC; $28 \mathrm{~d}$ flexural strength up to $13.45 \mathrm{MPa}, 18.92 \%$ increase over the reference RPC.

Effect on the mechanical properties of polypropylene fiber single RPC's. RPC single mixed with polypropylene fiber 3d, 28d compressive and flexural strength as well as the Figure 2:
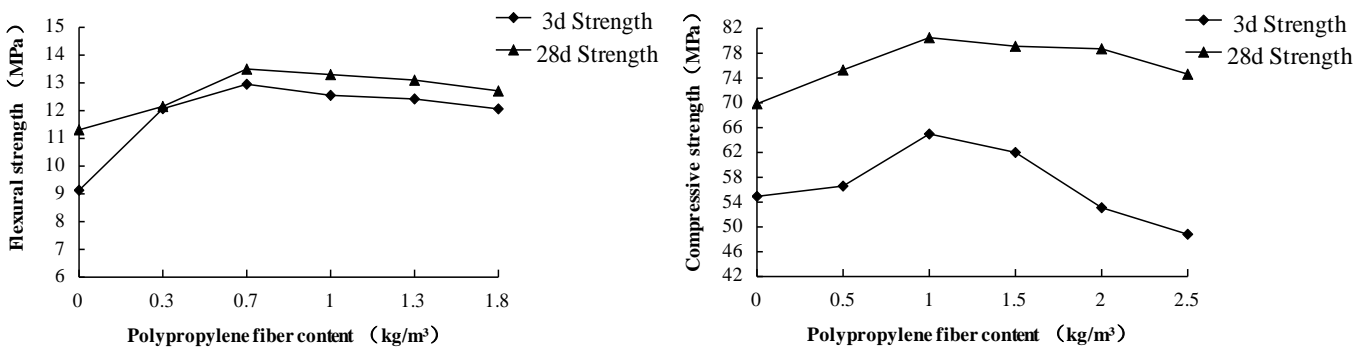

Fig.2 The effect of different dosage strength of polypropylene fibers for RPC

It can be seen by Figure 2, RPC 28d compressive strength of up to $80.5 \mathrm{MPa}, 15.25 \%$ increase over the reference RPC; $28 \mathrm{~d}$ flexural strength of up to $13.5 \mathrm{MPa}, 19.36 \%$ increase over the reference RPC.

Steel fiber and polypropylene fiber mixed with double impact on RPC's. RPC double steel fiber and polypropylene fiber 3d, 28d compressive and flexural strength, and fold under pressure, such as in Table 3 and Figure 3:

Tab.3 Different dosage of steel fiber and polypropylene fiber mixed with impact on RPC strength

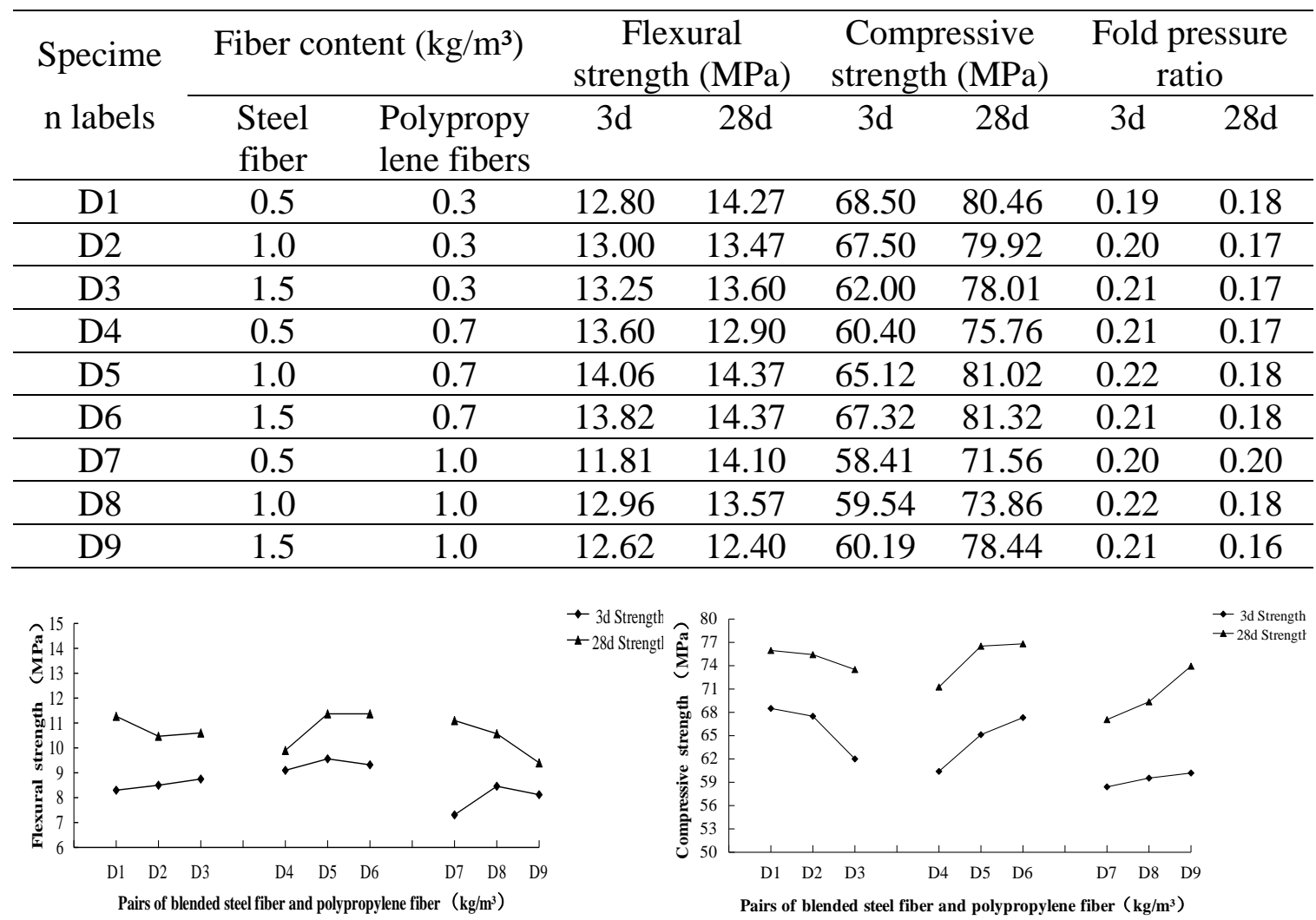

Fig.3 Pairs of blended steel fiber and polypropylene fiber on RPC intensity 
By Table 1 and Figure 3 shows that when the steel fiber incorporation of 1.5\% polypropylene fiber incorporation of $0.7 \%$, RPC 28d compressive strength of up to $81.32 \mathrm{MPa}$, flexural strength 14.37MPa, respectively than reference RPC improved $16.42 \%$ and $27.06 \%$.

Impact experiments and splitting test. By experiment, contrast benchmarks RPC,single steel fiber RPC,Single polypropylene fiber RPC and steel fiber polypropylene fiber, double mixed RPC impact resistance and resistance to splitting performance,For example, Table 4 below.Single steel fiber and polypropylene fiber RPC shock and cleavage strength is higher than the benchmark RPC,This shows that the fiber can increase the RPC flexible, and also more than the folding the benchmark RPC improve a lot, which further showed that fiber can reduce the brittleness of the RPC.When the double steel fiber content of $1.5 \%$ and $0.7 \%$ polypropylene Volume Fly, impact resistance of achieve the highest value to RPC is $1.1 \mathrm{MPa}$, increase $144.4 \%$ higher than the reference RPC; Anti-splitting strength highest 8.51MPa, higher than the benchmark RPC $143.7 \%$. At this time RPC toughness and ductility has been greatly improved, thereby increasing the durability, are also fully embodies the composites " Synergistic".

Tab.4 Effect of different blending amount fiber to splitting strength and the impact of the RPC

\begin{tabular}{|c|c|c|c|c|c|c|c|c|c|c|c|}
\hline \multirow[t]{2}{*}{$\begin{array}{l}\text { The specimen } \\
\text { reference numeral }\end{array}$} & \multirow{2}{*}{$\begin{array}{l}\text { Steel } \\
\text { fiber } \\
\text { content } \\
\left(\mathrm{kg} / \mathrm{m}^{3}\right)\end{array}$} & \multirow{2}{*}{$\begin{array}{c}\text { Polypr } \\
\text { opylen } \\
\text { e fiber } \\
\text { content } \\
\left(\mathrm{kg} / \mathrm{m}^{3}\right. \\
)\end{array}$} & \multicolumn{2}{|c|}{$\begin{array}{l}\text { Tensile } \\
\text { strength } \\
(\mathrm{MPa})\end{array}$} & \multicolumn{2}{|c|}{$\begin{array}{l}\text { Compressive } \\
\text { strength } \\
\text { (MPa) }\end{array}$} & \multicolumn{3}{|c|}{$\begin{array}{l}\text { Fold } \\
\text { pressure } \\
\text { ratio }\end{array}$} & \multirow{2}{*}{$\begin{array}{c}\text { Impact } \\
\text { resista } \\
n t \\
\text { Value } \\
(\mathrm{MPa})\end{array}$} & \multirow[t]{2}{*}{$\begin{array}{l}\text { Anti-spli } \\
\text { tting } \\
\text { values } \\
(\mathrm{MPa}) \\
\end{array}$} \\
\hline & & & $3 d$ & $28 d$ & 3d & $28 d$ & 3d & \multicolumn{2}{|c|}{$28 \mathrm{~d}$} & & \\
\hline RPC reference & 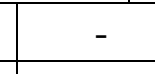 & $\begin{array}{l}- \\
\end{array}$ & 9.13 & 11.31 & 54.92 & 69.85 & \multicolumn{2}{|c|}{0.17} & 0.16 & 0.45 & 2.26 \\
\hline Single steel fiber RPC & 1 & - & 12.68 & 13.45 & 61.13 & 80.30 & \multicolumn{2}{|c|}{0.21} & 0.17 & 0.88 & 7.51 \\
\hline $\begin{array}{c}\text { Single-doped } \\
\text { polypropylene Fiber } \\
\text { RPC }\end{array}$ & 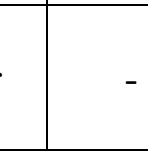 & 0.7 & 12.95 & 13.5 & 58.70 & 80.5 & \multicolumn{2}{|c|}{0.22} & 0.17 & 0.5 & 7.02 \\
\hline $\begin{array}{l}\text { Steel fiber } \\
\text { polypropylene fiber } \\
\text { Double mixed RPC }\end{array}$ & 1.5 & 0.7 & 13.82 & 14.37 & 67.32 & 81.32 & 0.21 & 0.18 & & 1.1 & 8.51 \\
\hline
\end{tabular}

\section{Test results and mechanism analysis}

RPC is mainly composed of cement, fly ash, quartz sand, high efficiency water reducing agent and silica powder and so on. RPC eliminates coarse aggregate interface effect and meet the close packing theory. With the deepening of cement hydration, strength of concrete is rising and plasticity is decreasing, coupled with a smaller RPC water-cement ratio, concrete will have a greater self-contraction. This contraction causes internal stress of concrete have a lot of micro-cracks in the stress-strain growth phase, the internal micro-cracks of RPC is stable. With the load increasing, the opening mode crack became active, because tensile stress is not very high at that time, tensile stress cracks borne by the steel fibers mainly. Fiber is tiny, number, uniform distribution, easy to form a mesh structure, reducing the plastic shrinkage of RPC and reducing early initial defect inside.

As the steel fiber has a high elastic modulus, good ductility, deformation ability, when the load further increases, the expansion of micro-cracks will be bound by steel webs[2]. On the other hand, over the cracks of steel fiber can spread out tensile stress effectively, so at this time has not yet appeared visible cracks.

With load increased further, splitting sound obvious, concrete specimen damage. It is seen A photograph from Figure 4, although the surface of steel fibers attached to more hydration products, suggesting that adhesion between steel fiber and concrete is better. But because the steel fibers have a high modulus of elasticity, so that the steel fibers are gradually pulled out when the specimen failure occurs. In this process it will be spread out a lot of tensile stress, so the steel fiber can increase the ductility and toughness of concrete. 


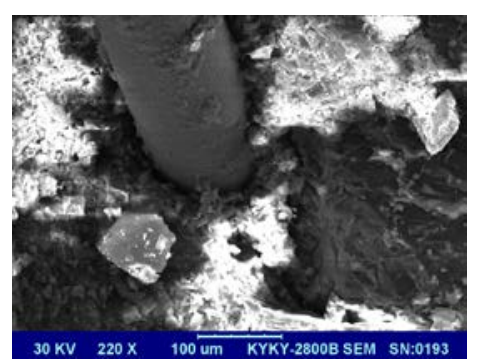

A single steel fiber

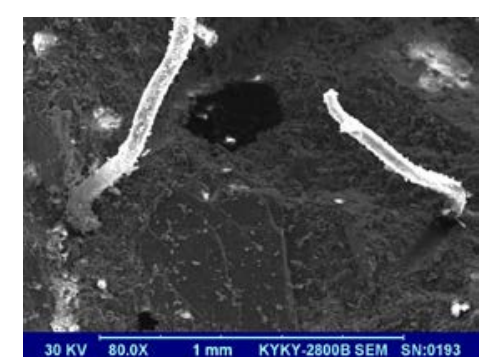

B single polypropylene fiber

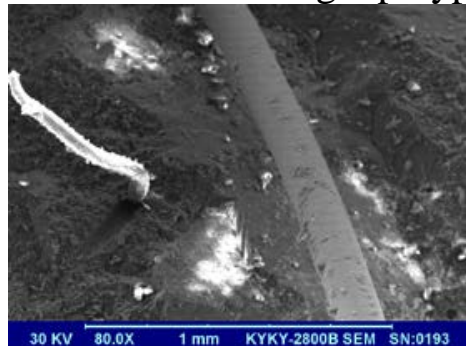

C double-doped steel fiber and polypropylene fiber

Fig.4 RPC in SEM photographs of different fibers

Because the water-cement ratio of RPC is small and no coarse aggregate, and therefore concrete interface zone is no longer weak area. Polypropylene has good dispersion, and at the same dosage intake conditions, the number of polypropylene fiber is more, the whole than steel fiber lap role function better[3]. Although the elastic modulus polypropylene fiber is much lower than steel fibers, but bond strength polypropylene fiber is much better than steel fiber. The picture B in Figure 4 shows that polypropylene fibers due to bending forces and pulled off the destruction, this damage mode and steel fiber completely different. Polypropylene fibers pulled off the destruction process will consume and absorb a lot of tensile stress. So with the fiber increasing, the RPC flexural compressive strength has a certain level of increase, but excessive dosage can cause polypropylene fiber agglomeration, dispersed unevenly, so strength will be reduced.

Steel fiber can effectively improve the toughness and ductility of the concrete, while polypropylene fibers can effectively hinder micro cracks, confounding both steel fiber and polypropylene fibers will impact resistance and crack resistance of concrete has increased significantly. This fully reflects the composite "Synergistic".

\section{Conclusions}

Single steel fiber concrete 28d flexural compressive strength of RPC, Highest were 13.45MPa and 80.3MPa, than the reference RPC increased by $18.92 \%$ and $14.96 \%$.

Single mixed polypropylene fiber RPC flexural compressive strength of concrete 28d,the highest respectively is $13.5 \mathrm{MPa}$ and $80.5 \mathrm{MPa}$, than the reference RPC increased by $19.36 \%$ and $15.25 \%$. When steel fiber content of $1.5 \%$, polypropylene fiber content of $0.7 \%, \mathrm{RPC}$ 's $28 \mathrm{~d}$ highest flexural and compressive strength were 14.37MPa 81.32MPa, RPC than the benchmark increased by $27.06 \%$ and $16.42 \%$. At this time of impact strength and resistance to splitting strength reached the highest value, were $1.1 \mathrm{MPa}$ and $8.51 \mathrm{Mpa}, 144.4 \%$ increase over the reference RPC and anti-split strength increased by $143.7 \%$.Two double-doped greatly improved toughness and ductility of RPC, fully reflects the composite materials"Synergistic".

\section{Acknowledgement}

This work was financially supported by the Jilin Science and Technology Foundation . 


\section{References}

[1] Juan-hong LIU, Shao-min SONG, Preparation, properties and microstructure of reactive powder concrete ,M. Beijing: chemical industry press, 2013:1-5

[2] Xu-ming GAO, Research on the performance of UHPC with steel fiber, J.Xiangtan University of Science and Technology. 2013:15-18

[3] Hao WU, Study on affection of polypropylene fiber to concrete cracks in the early age, J.Beijing institute of civil engineering and construction. 2012:11-13 